\title{
An Efficient Chloride Ingress Model for Long-Term Lifetime Assessment of Reinforced Concrete Structures Under Realistic Climate and Exposure Conditions
}

\author{
Phu Tho Nguyen ${ }^{1}$, Emilio Bastidas-Arteaga ${ }^{1), *}\left(\mathbb{D}\right.$, Ouali Amiri ${ }^{1,2)}$, and \\ Charbel-Pierre El Soueidy ${ }^{1)}$
}

(Received August 23, 2016, Accepted January 28, 2017, Published online May 19, 2017)

\begin{abstract}
Chloride penetration is among the main causes of corrosion initiation in reinforced concrete (RC) structures producing premature degradations. Weather and exposure conditions directly affect chloride ingress mechanisms and therefore the operational service life and safety of RC structures. Consequently, comprehensive chloride ingress models are useful tools to estimate corrosion initiation risks and minimize maintenance costs for RC structures placed under chloride-contaminated environments. This paper first presents a coupled thermo-hydro-chemical model for predicting chloride penetration into concrete that accounts for realistic weather conditions. This complete numerical model takes into account multiple factors affecting chloride ingress such as diffusion, convection, chloride binding, ionic interaction, and concrete aging. Since the complete model could be computationally expensive for long-term assessment, this study also proposes model simplifications in order to reduce the computational cost. Long-term chloride assessments of complete and reduced models are compared for three locations in France (Brest, Strasbourg and Nice) characterized by different weather and exposure conditions (tidal zone, de-icing salts and salt spray). The comparative study indicates that the reduced model is computationally efficient and accurate for long-term chloride ingress modeling in comparison to the complete one. Given that long-term assessment requires larger climate databases, this research also studies how climate models may affect chloride ingress assessment. The results indicate that the selection of climate models as well as the considered training periods introduce significant errors for mid- and long- term chloride ingress assessment.
\end{abstract}

Keywords: reinforced concrete, chloride ingress, moisture transport, heat transfer, corrosion, long-term assessment, weather condition.

\section{Introduction}

Chloride ingress is among the principal causes of deterioration of reinforced concrete (RC) structures in chloridecontaminated environments leading to important serviceability and safety reductions as well as increasing repair and maintenance costs (Bastidas-Arteaga and Schoefs 2012, 2015; Imam et al. 2015; Kim et al. 2016). For example, about 173,000 bridges on the interstate system of the United States are structurally deficient or functionally obsolete due in part to corrosion (Bhide 2008; Pritzl et al.

\footnotetext{
${ }^{1)}$ Institute for Research in Civil and Mechanical Engineering/Sea and Littoral Research Institute, CNRS UMR 6183/FR 3473, UBL, Université de Nantes, GeM, 2 Rue de la Houssinière, Nantes Cedex 3, BP 92208, 44322 Nantes, France.

*Corresponding Author;

E-mail: emilio.bastidas@univ-nantes.fr

${ }^{2)}$ IUT de Saint-Nazaire, 58 Rue Michel Ange, 44600 Saint-Nazaire, France.
}

Copyright $($ The Author(s) 2017. This article is an open access publication
2014; Radlińska et al. 2014). Concrete provides physical and chemical protection to the reinforcing steel in these environments where the chloride sources are external (seawater, de-icing salts, and salt spray) or internal (chlorides from concrete mixing). Most part of RC structures located in maritime and coastal zones are subjected to chloride through salt spray and seawater. Some RC structures located inland are exposed to de-icing salt during cold seasons.

Chloride ingress into concrete is a complex mechanism that could be influenced by the following circumstances:

- The chloride concentration of the surrounding environment varies over time.

- The amount of chloride in contact with concrete depends on its exposure to the surrounding environment which can be classified into four zones: submerged, tidal, splash and salt spray.

- The material properties change over time and are influenced by environmental conditions (e.g., temperature and relative humidity).

Among these factors, experimental evidence indicates that chloride penetration is highly affected by environmental conditions through temperature and humidity. For example, 
climate change can lead to lifetime reductions ranging from 2 to $18 \%$ for RC structures subjected to continental, tropical and oceanic weather conditions (Bastidas-Arteaga et al. 2010; Bastidas-Arteaga and Stewart 2015). Wang (2010) also confirms similar conclusions concerning the effects of climate change on RC durability.

The chloride-induced corrosion of steel reinforcement has been a critical issue for the service life assessment of RC structures. Therefore, several investigations have been carried out to understand and model chloride ingress and steel corrosion processes (Andrade and Alonso 1996; MartinPérez 1999). Before studying corrosion propagation, it is very important to understand chloride ingress processes. Chloride penetrates into concrete by different mechanisms such as diffusion, convection, migration, absorption, permeation, and thermo-diffusion. The Fick's law and NernstPlanck equations are most commonly used in the literature to model chloride penetration into concrete. Analytical solutions of these equations are often used for engineering purposes (Liu and Weyers 1998; Morga and Marano 2015; Pang and Li 2016; Srubar 2015; Xi and Bažant 1999). These models are valid under the following assumptions (Tuutti 1982): (a) concrete is saturated (permanently submerged in seawater), (b) concrete is homogeneous, (c) chloride coefficient diffusion is constant (in time and in space), and (d) surface chloride concentration is constant in time. The latter may be less restrictive than the others. In a recent research, de Vera et al. (2015) used the Fick's second law of diffusion to model chloride ingress into concrete structures exposed to atmospheric environment assuming that the chloride flux is constant. Under this assumption it is possible to consider a time-variant surface chloride concentration. However, the fickian diffusion-based models are limited when different transfer phenomena are involved. Nernst-Planck equations are commonly used for modeling chloride ingress in non-saturated concrete structures located in tidal zones and inland under salt spray attack or de-icing salt (Nielsen and Geiker 2003; Samson and Marchand 2007; Amiri et al. 2015). Chloride ingress through unsaturated concrete is a complex problem involving diffusion, convection, chemical interaction, water activity, and thermo-gradient transfer terms. Nernst-Planck equations can be then coupled with moisture transport and heat transfer relationships to establish a complete model of chloride ingress. In addition, these models account for other factors such as: chloride binding, ionic interaction, aging factor, temperature, humidity (Bastidas-Arteaga et al. 2011; Martin-Pérez 1999).

Estimation of corrosion initiation time in RC structures is crucial for minimizing both maintenance costs and failure risks (Bastidas-Arteaga and Stewart 2015). The advantage of analytical solutions of Fick's law is their low computational cost; however, these models cannot represent accurately chloride ingress under real (complex) exposure conditions, leading to poor prediction. This point is improved by Nernst-Planck based models but they are generally computationally expensive (Marchand and Samson 2009). Its computational efficiency is affected directly by the type of chloride ingress model and the time discretization step. Complex chloride ingress models take into consideration more interactions among transfer phenomena (e.g., chloride ingress mechanisms, water activity, and thermo-gradient transfer, etc.). Nevertheless its relatively high computational cost poses a serious problem to estimate corrosion initiation time. In particular, when lifetime assessment includes the uncertainties involved in this problem (Bastidas-Arteaga et al. 2010, 2011, 2013).

The assessment of corrosion initiation risks also requires long-term and high-resolution climate simulated databases for a given location. Such databases are rarely found in practice where over-simplified models are used to represent deterministic (Martin-Pérez 1999) or probabilistic (BastidasArteaga et al. 2013; Breysse et al. 2014) climate parameters. The use of over-simplified climate models as well as the selection of time resolutions introduces additional errors for lifetime assessment. Time-averaged exposure data neglects important climate variations leading to the reduction of chloride ingress penetration rates (Flint et al. 2014); therefore, understanding the influence of these aspects becomes essential to improve the accuracy of chloride ingress modeling.

Within this context, the purposes of this study are:

- To introduce a complete model of chloride ingress that takes into account: concrete chloride binding capacity, time-dependent nature and effects of temperature and humidity in the surrounding environment, time-dependent diffusion and chloride flow into unsaturated concrete considering water activity, and interaction between chloride content and water vaporization.

- To establish an efficient (reduced) chloride ingress model ensuring a good accuracy (with respect to the complete model) with reduced computational effort for long-term lifetime assessment under realistic climate and exposure conditions.

- To study the effects of time discretization step and climate models on the corrosion initiation time assessment for specific weather conditions.

The paper is organized as follows. Section 2 describes the chloride ingress models (complete and reduced) as well as the initial and boundary conditions. Section 3 presents the climate databases (temperature air, temperature water and relative humidity) and climate models that are considered in the numerical example. Section 4 evaluates the performance of the reduced model for various realistic climate and exposure conditions and provides recommendations for each case. Section 4 also includes a discussion about the use of simulated climate data for lifetime assessment.

\section{Modeling Chloride Ingress}

Chloride ingress is governed by different phenomena such as moisture transport, heat transfer and chloride transfer. The 
following sections describe each phenomenon through transfer equations at the macroscopic scale.

\subsection{Complete Model of Chloride Transfer 2.1.1 Modeling Moisture Transport}

Moisture transfer is a driving factor for multi-physical chloride ingress models. It can be modeled using Darcy's law with main capillary pressure or humidity diffusion. Main capillary pressure takes into account the vapor transfer that influences condensation and vaporization for low moisture content in concrete (Baroghel-Bouny et al. 2011; Mualem 1976). Humidity diffusion is a quite empirical approach that uses average moisture diffusion coefficients (Martin-Pérez 1999). This work considers a moisture transport model based on humidity diffusion according to Darcy's law and thermodiffusion generated by a temperature gradient that requires therefore the knowledge of sorption-desorption curves (Nguyen and Amiri 2016):

$$
\frac{\partial \mathrm{W}}{\partial \mathrm{t}}+\operatorname{div}(\underbrace{\mathrm{D}_{\mathrm{h}} \frac{\partial \mathrm{W}}{\partial \mathrm{x}}}_{\text {humidity diffusion }}+\underbrace{\mathrm{D}_{\mathrm{T}} \frac{\partial \mathrm{T}}{\partial \mathrm{x}}}_{\text {thermo-diffusion }})=0
$$

where $\mathrm{W}$ is the moisture content $\left(\mathrm{m}^{3}\right.$ water $/ \mathrm{m}^{3}$ concrete $)$ at depth $\mathrm{x}$ and time $\mathrm{t}, \mathrm{T}$ is the temperature inside concrete $(\mathrm{K})$, $\mathrm{D}_{\mathrm{h}}$ and $\mathrm{D}_{\mathrm{T}}$ are respectively the humidity $\left(\mathrm{m}^{2} / \mathrm{s}\right)$ and thermodiffusion $\left(\mathrm{m}^{2} /(\mathrm{s} \times \mathrm{K})\right)$ coefficients that depend on weather conditions and material properties. These coefficients can be estimated from:

$$
\begin{aligned}
\mathrm{D}_{\mathrm{h}}= & \exp \left(\frac{\mathrm{E}_{\mathrm{h}}}{\mathrm{R}} \times\left(\frac{1}{\mathrm{~T}_{\mathrm{ref}}}-\frac{1}{\mathrm{~T}}\right)\right) \\
& \times\left(-\frac{\mathrm{K}_{\mathrm{w}} \mathrm{K}_{\mathrm{rw}}}{\mu_{\mathrm{w}}} \mathrm{W} \frac{\rho_{\mathrm{w}} \mathrm{R}_{\mathrm{v}} \mathrm{T}}{\mathrm{RH}}-\frac{\mathrm{P}_{\mathrm{vs}}}{\rho_{\mathrm{w}} \mathrm{R}_{\mathrm{v}} \mathrm{T}}(\epsilon-\mathrm{W}) \mathrm{D}_{\mathrm{va}}\right) \\
& \times \frac{\partial \mathrm{RH}}{\partial \mathrm{W}}
\end{aligned}
$$

and

$$
\mathrm{D}_{\mathrm{T}}=\frac{\mathrm{K}_{\mathrm{w}} \mathrm{K}_{\mathrm{rw}}}{\mu_{\mathrm{w}}} \mathrm{W} \frac{\mathrm{P}_{\mathrm{c}}}{\mathrm{T}}-\frac{1}{\rho_{\mathrm{w}}} \frac{\mathrm{RH}}{\mathrm{R}_{\mathrm{v}}}(\epsilon-\mathrm{W}) \mathrm{D}_{\mathrm{va}} \frac{\partial\left(\frac{\mathrm{P}_{\mathrm{vs}}}{\mathrm{T}}\right)}{\partial \mathrm{T}}
$$

where $E_{h}$ is the activation energy of moisture transfer process $(\mathrm{J} / \mathrm{mol}), \mathrm{R}$ is the gas constant $(8.314 \mathrm{~J} / \mathrm{mol} \mathrm{K}), \mathrm{T}_{\text {ref }}$ is the reference temperature chosen equal to $20{ }^{\circ} \mathrm{C}, \mathrm{K}_{\mathrm{w}}$ is the permeability to water of concrete $\left(\mathrm{m}^{2}\right), \mathrm{K}_{\mathrm{rw}}$ is the relative permeability to water of concrete $(-), \mu_{\mathrm{w}}$ is the water viscosity $(\mathrm{Pa} \times \mathrm{s}), \rho_{\mathrm{w}}$ is the density of water $\left(\mathrm{kg} / \mathrm{m}^{3}\right), \mathrm{R}_{\mathrm{v}}$ is the specific gaz constant $(461.89 \mathrm{~J} /(\mathrm{kg} \times \mathrm{K})), \epsilon$ is the porosity of concrete $(-), \mathrm{RH}$ is the relative humidity inside concrete, $\mathrm{P}_{\mathrm{vs}}$ is the saturated vapor pressure $(\mathrm{Pa})$ that can be expressed as below:

$$
\mathrm{P}_{\mathrm{vs}}=\exp \left(13.7-\frac{5120}{T}\right)
$$

The capillary pressure $\mathrm{P}_{\mathrm{c}}(\mathrm{Pa})$ can be calculated through the Kelvin's Equation:

$$
\mathrm{P}_{\mathrm{c}}=-\frac{\rho_{\mathrm{w}}}{\mathrm{M}_{\mathrm{w}}} \times \mathrm{RT} \times \ln (\mathrm{RH})
$$

where $\mathrm{M}_{\mathrm{w}}$ is the molecular weight of water $(18 \mathrm{~g} / \mathrm{mol})$. There is a relation between the relative humidity and moisture content [Eq. (8)]. From Eqs. (5), (8) and (9) we can determine the capillary pressure according to the moisture content.

The vapor diffusion coefficient in gas $\mathrm{D}_{\mathrm{va}}\left(\mathrm{m}^{2} / \mathrm{s}\right)$ can be determined as follows (Mualem 1976):

$$
\mathrm{D}_{\mathrm{va}}=2.17 \times 10^{-5}\left(\frac{\mathrm{T}}{\mathrm{T}_{\text {ref }}}\right)^{1.88} \times \epsilon^{-2} \times(\epsilon-\mathrm{W})^{2 \mathrm{~m}+2}
$$

where $\mathrm{m}$ is a factor representing concrete skeleton resistance to gas equal to 1.4 (-) (Mualem 1976; Sleiman et al. 2009).

Sorption isotherm describes relation between moisture content of concrete $\left(\mathrm{m}^{3}\right.$ water $/ \mathrm{m}^{3}$ concrete) and relative humidity of concrete. This relation is expressed as (Genuchten 1980; Mualem 1976):

$$
\frac{\mathrm{W}}{\epsilon}=\left(1+(-\alpha \times \ln \mathrm{RH})^{\frac{1}{1-\beta}}\right)^{-\beta}
$$

where $\alpha$ and $\beta$ are empirical parameters defined by (Genuchten 1980) and represent sorption-desorption curves. The moisture diffusion coefficient of Eqs. (1) and (2) includes vapor movement. In case of a concrete exposed to very low humidity, the vapor flow can be more important than liquid water flow. In addition, in the present work, we take into account the chloride effect on the water retention capacity of concrete. Indeed, the presence of chloride in pore solution reduces liquid water evaporation. This may slow down the moisture transport, especially in case of low relative humidity. The sorption curve is thus mathematically described as follows (Baroghel-Bouny et al. 1999):

$$
\frac{\mathrm{W}}{\epsilon}=\left(1+\left(-\alpha \times\left(\ln \mathrm{RH}-\ln \mathrm{a}_{\mathrm{w}}\right)\right)^{\frac{1}{1-\beta}}\right)^{-\beta}
$$

where $a_{w}$ is the water activity estimated from the following equation (Nguyen 2007):

$$
\ln \mathrm{a}_{\mathrm{w}} \cong-\frac{2 \mathrm{M}_{\mathrm{w}}}{\rho_{\mathrm{w}}} \times \mathrm{C}_{\mathrm{f}}
$$

where $\mathrm{C}_{\mathrm{f}}$ is the free chloride concentration that will be detailed in Sect. 2.1.3.

From the sorption curve, we can determine relative permeability to water that describes the effective permeability of liquid phase in concrete as (Mualem 1976):

$$
\mathrm{K}_{\mathrm{rW}}\left(\frac{\mathrm{W}}{\epsilon}\right)=\left(\frac{\mathrm{W}}{\epsilon}\right)^{5,5} \times\left(1-\left(1-\left(\frac{\mathrm{W}}{\epsilon}\right)^{\frac{1}{\beta}}\right)^{\beta}\right)^{2}
$$

The relative permeability varies from 0 to 1 . It equals 1 when concrete is saturated with water. Equation (10) takes into account the discontinuity of the liquid phase at very low 
humidity of concrete by fixing the relative permeability of concrete to zero.

\subsubsection{Modeling Heat Transfer}

Several approaches have been developed to predict temperature evolution in cement based materials (Jensen and Hansen 1999; Samson and Marchand 2007). The most common methods are based on a single mass conservation equation with average parameters. We can find in the literature complex models of heat transfer involving the contribution of all phases (gas, liquid, solid), hydration process energy, convection and conduction (Martin-Pérez 1999). For a prediction of long-term behavior, in most cases, energy associated with water vaporization, gas movement and hydration would become weak as compared to the conduction. Therefore, the heat transfer equation can be written as follows:

$$
\frac{\partial \mathrm{T}}{\partial \mathrm{t}}-\frac{1}{\rho_{0} \times \mathrm{C}_{\mathrm{p}}} \times \operatorname{div}(\underbrace{\lambda \operatorname{grad} \mathrm{T}}_{\text {conduction }})=0
$$

where $\rho_{0}$ is the density of concrete $\left(\mathrm{kg} / \mathrm{m}^{3}\right), \mathrm{C}_{\mathrm{p}}$ is the effective heat specific of concrete $(\mathrm{J} /(\mathrm{kg} \times \mathrm{C}))$ and $\lambda$ is the heat conductivity of concrete $(\mathrm{W} /(\mathrm{m} \times \mathrm{C}))$ that depends on weather conditions and material properties and that can be determined from (Samson and Marchand 2007):

$$
\lambda=\left\{\begin{array}{l}
\lambda_{\text {ref }} \times\left(0.244\left(\frac{\mathrm{w}}{\epsilon}-1\right)+1\right) \\
\times\left(0.0015\left(\mathrm{~T}-\mathrm{T}_{\text {ref }}\right)+1\right) \text { if } \mathrm{T} \geq-4{ }^{\circ} \mathrm{C} . \\
\lambda=1.5 \text { if } \mathrm{T}<-4{ }^{\circ} \mathrm{C}
\end{array}\right.
$$

where $\lambda_{\text {ref }}$ is the reference concrete heat conductivity measured for a given temperature-e.g., $\mathrm{T}_{\text {ref }}=20^{\circ} \mathrm{C}$. $\lambda$ linearly increases with the moisture content of concrete.

Equation (12) could account for freezing and thawing situations. Indeed, $\lambda$ is assumed constant for negative temperatures. Above the threshold $\left(\mathrm{T} \geq-4{ }^{\circ} \mathrm{C}\right), \lambda$ increases linearly with the temperature.

\subsubsection{Modeling Chloride Transfer}

According to Samson and Marchand (2007), chloride transfer is modeled by the mass balance equation including diffusion, convection, chemical activity and thermo-diffusion terms:

$$
\begin{aligned}
& \frac{\partial\left(\mathrm{WC}_{\mathrm{f}}\right)}{\partial \mathrm{t}}+\frac{\partial \mathrm{C}_{\mathrm{b}}}{\partial \mathrm{C}_{\mathrm{f}}} \times \frac{\partial \mathrm{C}_{\mathrm{f}}}{\partial \mathrm{t}} \\
& -\operatorname{div}(\underbrace{\mathrm{D}_{\mathrm{e}} \mathrm{W} \operatorname{grad} \mathrm{C}_{\mathrm{f}}}_{\text {diffusion }}+\underbrace{\mathrm{C}_{\mathrm{f}} \mathrm{D}_{\mathrm{W}} \operatorname{gradW}}_{\text {convection }} \\
& +\underbrace{\mathrm{D}_{\mathrm{e}} \mathrm{C}_{\mathrm{f}} \mathrm{Wgrad}\left(\ln \gamma_{\mathrm{Cl}}\right.}_{\text {chemical activity }}+\underbrace{\mathrm{W} \mathrm{D}_{\mathrm{e}} \mathrm{C}_{\mathrm{f}} \frac{1}{\mathrm{~T}} \ln \left(\gamma_{\mathrm{Cl}} \times \mathrm{C}_{\mathrm{f}}\right) \operatorname{grad} \mathrm{T}}_{\text {thermo-diffusion }}) \\
& =0
\end{aligned}
$$

where $C_{f}$ is the free chloride concentration $\left(\mathrm{mol} / \mathrm{m}^{3}\right.$ solution), $\mathrm{C}_{\mathrm{b}}$ is the bound chloride concentration $\left(\mathrm{mol} / \mathrm{m}^{3}\right.$ concrete), $\gamma_{\mathrm{Cl}}$ is the chemical activity coefficient for chlorides that depends on the free chloride concentration, $\mathrm{D}_{\mathrm{W}}$ is the liquid water diffusion coefficient $\left(\mathrm{m}^{2} / \mathrm{s}\right)$ that can be expressed as follows:

$$
\begin{aligned}
\mathrm{D}_{\mathrm{W}}= & \exp \left(\frac{\mathrm{E}_{\mathrm{h}}}{\mathrm{R}} \times\left(\frac{1}{\mathrm{~T}_{\mathrm{ref}}}-\frac{1}{\mathrm{~T}}\right)\right) \times\left(-\frac{\mathrm{K}_{\mathrm{w}} \mathrm{K}_{\mathrm{rw}}}{\mu_{\mathrm{w}}} \mathrm{W} \frac{\rho_{\mathrm{w}} \mathrm{R}_{\mathrm{v}} \mathrm{T}}{\mathrm{RH}}\right) \\
& \times \frac{\partial \mathrm{RH}}{\partial \mathrm{W}}
\end{aligned}
$$

$D_{e}$ is the coefficient of chloride transfer $\left(\mathrm{m}^{2} / \mathrm{s}\right)$ that takes into account temperature, moisture, age of concrete and free chloride concentration:

$$
D_{e}=D_{C l, \text { ref }} \times f_{1}(T) \times f_{2}(t) \times f_{3}(W) \times f_{4}\left(C_{f}\right)
$$

where $\mathrm{D}_{\mathrm{Cl}, \text { ref }}$ is the reference diffusion coefficient measured at standard conditions, $f_{1}(T)$ is a function that takes into account the effect of the temperature:

$$
\mathrm{f}_{1}(\mathrm{~T})=\exp \left(\frac{\mathrm{E}_{\mathrm{a}}}{\mathrm{R}} \times\left(\frac{1}{\mathrm{~T}_{\text {ref }}}-\frac{1}{\mathrm{~T}}\right)\right)
$$

where $E_{a}$ is the activation energy of chloride transfer process. $f_{2}(t)$ is a function that considers the effect of concrete aging:

$$
\mathrm{f}_{2}(\mathrm{t})=\left(\frac{\mathrm{t}_{\mathrm{ref}}}{\mathrm{t}}\right)^{\mathrm{m}_{\mathrm{age}}}
$$

where $t_{r e f}$ is the time of exposure at which $D_{C 1, \text { ref }}$ has been measured $\left(t_{\text {ref }}=28\right.$ days), $t$ is the actual exposure time (days) and $\mathrm{m}_{\text {age }}$ the age factor $(-) \cdot \mathrm{f}_{3}(\mathrm{~W})$ is a function accounting for the moisture content dependence (Buchwald 2000):

$$
\mathrm{f}_{3}(\mathrm{~W})=\left(\frac{\mathrm{W}}{\epsilon}\right)^{\frac{7}{3}}
$$

$\mathrm{f}_{4}\left(\mathrm{C}_{\mathrm{f}}\right)$ is a function that considers chloride concentration effect on chloride diffusion process (Damrongwiriyanupap et al. 2015):

$$
\mathrm{f}_{4}\left(\mathrm{C}_{\mathrm{f}}\right)=1-\mathrm{k}_{\text {ion }} \times\left(\mathrm{C}_{\mathrm{f}}^{\mathrm{c}}\right)^{\mathrm{m}_{\text {ion }}}
$$

where $\mathrm{k}_{\text {ion }}$ and $\mathrm{m}_{\text {ion }}$ are empirical parameters $\left(\mathrm{k}_{\mathrm{ion}}=8.33\right.$, $\left.\mathrm{m}_{\mathrm{ion}}=0.5\right)$ (Damrongwiriyanupap et al. 2015) and $\mathrm{C}_{\mathrm{f}}^{\mathrm{c}}$ is the free chloride concentration $(\mathrm{kg} / \mathrm{kg}$ concrete).

The chemical activity coefficient can be determined as (Samson and Marchand 2007):

$$
\operatorname{In} \gamma_{\mathrm{Cl}}=-\frac{\sqrt{2} \times \mathrm{F}^{2} \times \mathrm{e}_{0}}{8 \pi \times\left(\varepsilon_{r} \varepsilon_{0} \mathrm{RT}\right)^{1.5}} \times \mathrm{z}_{\mathrm{Cl}}^{2} \times \sqrt{\mathrm{C}_{\mathrm{f}}}
$$

where $\mathrm{F}$ is the Faraday constant $(96,500 \mathrm{C} / \mathrm{mol}), \mathrm{e}_{0}$ is the elementary charge $\left(1.6 \times 10^{-19} \mathrm{C}\right), \varepsilon_{r}$ is the relative permittivity of water $\left(\varepsilon_{r}=80\right), \varepsilon_{0}$ is the vacuum permittivity $\left(\varepsilon_{0}=8.82 \times 10^{-12} \mathrm{~A}^{2} \times \mathrm{s}^{4} /\left(\mathrm{kg} \times \mathrm{m}^{3}\right)\right.$ and $\mathrm{z}_{\mathrm{cl}}$ is the chloride ion charge $\left(\mathrm{z}_{\mathrm{cl}}=-1\right)$. 
The bound chloride concentration depends mainly on concrete properties and free chloride concentration in pore solution. In general, it is determined experimentally. For concrete exposed to maritime conditions where chloride concentration is not high, the Langmuir isotherm provides the best description of bound chloride concentration (Larsen 1998; Tang and Nilsson 1993). This work uses this isotherm for calculating the bound chloride content as:

$$
\mathrm{C}_{\mathrm{b}}=\frac{\alpha_{\mathrm{i}} \mathrm{C}_{\mathrm{f}}}{1+\beta_{\mathrm{i}} \mathrm{C}_{\mathrm{f}}}
$$

where $\alpha_{\mathrm{i}}$ and $\beta_{\mathrm{i}}$ are parameters estimated experimentally.

This section presented a coupled thermo-hydro-chemical model for chloride ingress into concrete. The model involves major processes that occur during chloride penetration such as diffusion, convection, thermo-diffusion and chemical activity. It also takes into account temperature and moisture changes of the surrounding environment. The complete model expressed by the set of Eqs. (1-21) is hence accurate to predict the chloride ingress process. Nevertheless, it requires a high computational cost that could be restrictive for the long-term assessment of the corrosion initiation time in RC under realistic climate and exposure condition. Furthermore, the computational burden increases in the case of probabilistic assessment of RC structure durability. This problem could be dealt with a reduced numerical model or increasing the time-discretization step. Hence, the following section presents a reduced ingress chloride model. The illustrative examples (Sect. 4) compare results obtained from both the complete and reduced models and study the effects of the time-discretization steps for different types of exposure conditions.

\subsection{Reduced Model of Chloride Ingress}

This section presents a reduced model of chloride penetration based on the above-mentioned complete model. It retains the main terms of the coupled thermo-hydro-chemical transfer equations. The moisture transfer equations neglect thermo-diffusion terms and vapor flow by assuming that Darcy diffusion is the key parameter for humidity transfer:

$$
\begin{aligned}
\frac{\partial \mathrm{W}}{\partial \mathrm{t}}+ & \underbrace{\operatorname{div}\left(\mathrm{D}_{\mathrm{W}} \frac{\partial \mathrm{W}}{\partial \mathrm{x}}\right)}_{\text {humidity diffusion }}=0 \\
\mathrm{D}_{\mathrm{W}}= & \exp \left(\frac{\mathrm{E}_{\mathrm{h}}}{\mathrm{R}} \times\left(\frac{1}{\text { Tref }}-\frac{1}{\mathrm{~T}}\right)\right) \\
& \times\left(-\frac{\mathrm{K}_{\mathrm{W}} \mathrm{K}_{\mathrm{rw}}}{\mu_{\mathrm{w}}} \frac{\rho_{\mathrm{w}} \mathrm{R}_{\mathrm{v}} \mathrm{T}}{\mathrm{RH}}\right) \times \frac{\partial \mathrm{RH}}{\partial \mathrm{W}}
\end{aligned}
$$

This simplification could lead to wrong chloride assessment when the weather conditions are rather dry. Therefore, a comparison between complete and reduced models is necessary to validate this assumption.

The heat transfer equations remain unchanged [Eqs. (11) and (12)] Indeed, in the heat equations we have removed the heat flows from vapor diffusion and convection terms that are negligible as compared to the heat conduction (Samson and Marchand 2007). This model of heat transfer is able to take into account the humidity state of concrete despite these simplifications.

Concerning chloride transfer, it is assumed that the chemical activity and thermo-gradient terms are negligible because the gradient of the activity coefficient is practically zero for the considered range of chloride concentrations (de Vera et al. 2000; Hidalgo et al. 2001). The thermo-gradient term mainly depends on ionic diffusion, chemical activity and temperature gradient. The latter is weak because of a rapid heat transfer through concrete. The mass conservation equation of chloride transfer considers only the diffusion and convection terms and is written as:

$$
\begin{aligned}
& \frac{\partial \mathrm{WC}_{\mathrm{f}}}{\partial \mathrm{t}}+\frac{\partial \mathrm{C}_{\mathrm{b}}}{\partial \mathrm{C}_{\mathrm{f}}} \frac{\partial \mathrm{C}_{\mathrm{f}}}{\partial \mathrm{t}} \\
& -\operatorname{div}(\underbrace{\mathrm{D}_{\mathrm{e}} \mathrm{W} \operatorname{grad} \mathrm{C}_{\mathrm{f}}}_{\text {diffusion }}+\underbrace{\mathrm{C}_{\mathrm{f}} \mathrm{D}_{\mathrm{W}} \operatorname{gradW}}_{\text {convection }}) \\
& =0
\end{aligned}
$$

\subsection{Initial and Boundary Conditions}

\subsubsection{Initial Condition}

Initial conditions are required for solving the systems of partial differential equations (PDEs) for the complete [Eqs. (1), (11) and (13)] or the reduced [Eqs. (11), (22) and (24)] models. According to the literature (Zhang et al. 2012), the interior humidity of early-age concrete can be described by a vapor-saturated stage. Afterwards, the concrete humidity decreases gradually. This reduction depends on location and climate conditions. However, it is quite complicated to define the real humidity after early-age concrete. In this work, it is assumed that the concrete have reached a stable humidity when subjected to the external climate conditions. The initial relative humidity of concrete is set uniform across the whole concrete sample and equals $70 \%$ (Sleiman et al. 2009). The temperature of concrete depends highly on the surrounding environment temperature; its initial value is thus hypothetical. The temperature of concrete is considered uniform and equals $20^{\circ} \mathrm{C}$. Concerning initial chloride concentration, it is possible to have a low amount of chlorides inside concrete mix ingredients such as aggregate and cement. The chloride content can be provided by the manufacturer or experimentally determined. However, in general, the amount of chloride mixed in is low and can be neglected with respect to chloride coming from outside. Therefore, we suppose that the initial chloride content is equal to zero.

\subsubsection{Boundary Conditions}

The boundary conditions at the exposed surface are based on the flow of surrounding parameters (relative humidity, temperature and chloride concentration) crossing the concrete surface. In this work, we consider two configurations of exposure: wetting-drying cycles (tidal zone) and air exposure. For both configurations, the flux of $\psi$ (moisture, 
temperature, or chlorides) crossing the concrete surface, $\varphi_{\psi}^{\mathrm{s}}$ is expressed as:

$$
\varphi_{\psi}^{\mathrm{s}}=\underbrace{\mathrm{h}_{\psi}\left(\psi^{\mathrm{s}}-\psi_{\text {env }}\right)}_{\text {diffusion }}+\underbrace{\psi_{\text {env }} \varphi_{\psi}^{\text {s }}}_{\text {convection }}
$$

where $h_{\psi}$ is the surface transfer coefficient, $\psi^{\mathrm{s}}$ is the value of $\psi$ at the concrete exposed surface, $\psi_{\text {env }}$ is the surrounding environment parameter for each physical problem and $\varphi_{\psi}^{\prime s}$ is the convection flow at the exposed surface. Unlike air exposure, in wetting-drying cycles the surface transfer coefficients $h_{\psi}$ are very high, which leads to Dirichlet's boundary conditions.

This paper also considers that all transfers are unidirectional. Therefore, it is assumed that there are not additional fluxes of $\psi$ for the other surfaces. The climate evolution is thus taken into account by the variable $\psi_{\text {env }}$. In the case of partial immersion in seawater (tidal zone), concrete surface is exposed to cycles of wetting (6 h) and drying (18 h) during 1 day in accordance with the literature (Sleiman et al. 2009). When structure is exposed to salt spray, it is assumed that surface chloride concentration imposed at concrete exposed surface is constant. If the structure is subjected to de-icing salts, it is considered that during 5 months of cold periods, surface chloride concentration is also constant. In the section considering case studies, the values of surface chloride concentration are detailed.

\subsection{Numerical Resolution of Governing Transfer Equations}

This work focuses mainly on the assessment of chloride concentration at the concrete cover depth, $\mathrm{C}_{\mathrm{ac}}$, which is useful to estimate corrosion initiation risks. In order to calculate the chloride concentration inside a concrete structure and estimate the time to corrosion initiation, we need to solve the system of PDEs described in Sects. 2.1 and 2.2. Towards this aim, we use the finite volume method with two mesh sizes. The first mesh size $(50 \mathrm{~mm})$ is used to discretize the length from the concrete surface until the concrete cover depth $(5 \mathrm{~cm})$. The second one $(150 \mathrm{~mm})$ is used to discretize the material from the concrete cover depth until a maximum depth of $20 \mathrm{~cm}$.

Figure 1 summarizes the proposed algorithm used to estimate the evolution in time and depth of $\mathrm{T}, \mathrm{W}$ and $\mathrm{C}_{\mathrm{f}}$ inside concrete. After introducing the material properties and the initial conditions, the finite volume method is used to solve the heat transfer equations, then the moisture transport relationships and finally the chloride ingress equations. The solution of each transfer set of equations considers the evolution of exposure conditions at each time step dt. The system of PDEs is integrated by using the same dt. The computation is stopped when time exceeds a predefined structural lifetime $\left(\mathrm{T}_{\text {lifetime }}=100\right.$ year $)$ or when the chloride concentration at the rebar level exceeds a threshold chloride concentration for corrosion initiation $\mathrm{C}_{\text {crt }}=0.4 \%$ by weight of cement $\left(\approx 37 \mathrm{~mol} / \mathrm{m}^{3}\right.$ of concrete) (Duracrete 2000).

\section{Climate Data and Modeling Climate Evolution}

In order to consider the effect of various climate and exposure conditions, this study includes three localizations in France that represent three different climate configurations: Brest (Atlantic west coast where climate is temperate and humid), Strasbourg (mild continental climate where climate is continental with a cold winter), and Nice (mild Mediterranean climate where climate is hot and dry). The climate data was provided by Méteo France from instrumented sites located inland and on the seashore [https://donneespubliques.meteofrance.fr]. It includes relative humidity, air, and seawater temperatures (Sect. 3.1). Since in practice it is difficult to obtain long-term climate predictions, various climate models are also presented in Sect. 3.2. Section 4 will study the effects of these climate models in comparison to real climate data for long-term assessment of chloride ingress.

\subsection{Climate Database}

Figures 2, 3 and 4 show the climate database of Nice, Brest and Strasbourg for a period of 13 years from 2003 to 2015. The climate parameters (relative humidity, air and water temperature) were hourly recorded. This allows studying the effect of maximum or minimum daily climate variations on transfer processes. The data displayed in these figures indicate that the climate conditions are different for each place. Nice has a hot and dry climate, Brest has a cold and humid climate, and Strasbourg has a very cold and slightly humid climate. The Strasbourg climate has at least one negative temperature period per year. We study the effect of these different exposure conditions in Sect. 4. Since the assessment of corrosion initiation time requires a significant amount of climate data, we assume that the climate database cycle is 13 years periodic by using several times the 13 years database. This climate database is used as an input for the chloride ingress model in order to compute the evolution of chloride concentration at the rebar level.

\subsection{Modeling Climate Evolution}

This section concerns the modeling of three climate parameters: air, seawater temperatures and specific humidity. To assess impact of climate models on RC lifetime prediction, in the present work, we consider three different climate models. The two first models can represent daily climate variation. While the first one uses a yearly-based database to model daily climate variation, the second one uses a monthly-based database. The third model only takes into account seasonal climate variation. The following sections describe these models.

\subsubsection{Daily Climate Model Considering a Yearly Type Day (DYT)}

The DYT was utilized in some works in the literature (Yuan and Jiang 2011; Bastidas-Arteaga et al. 2013). This climate model includes average, seasonal and daily variation 


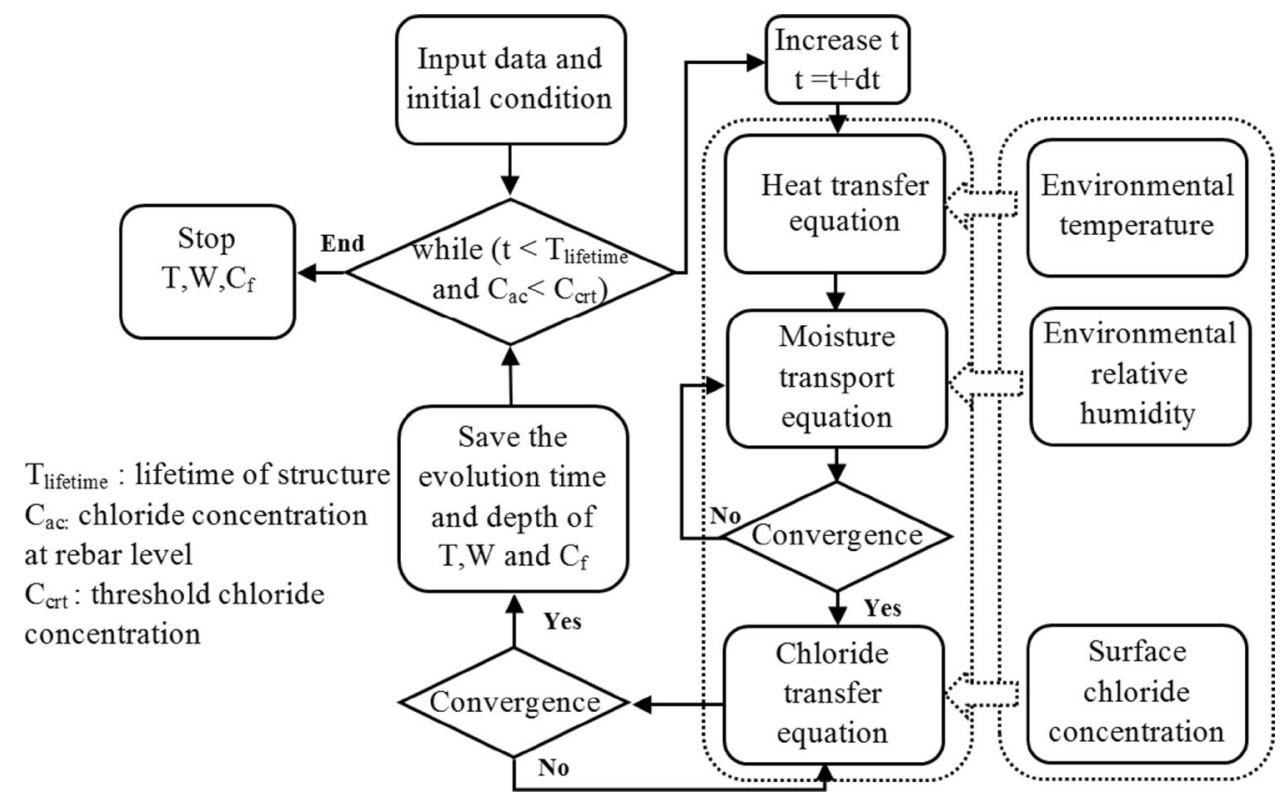

Fig. 1 Algorithm for calculating temperature, moisture content and chloride profiles.
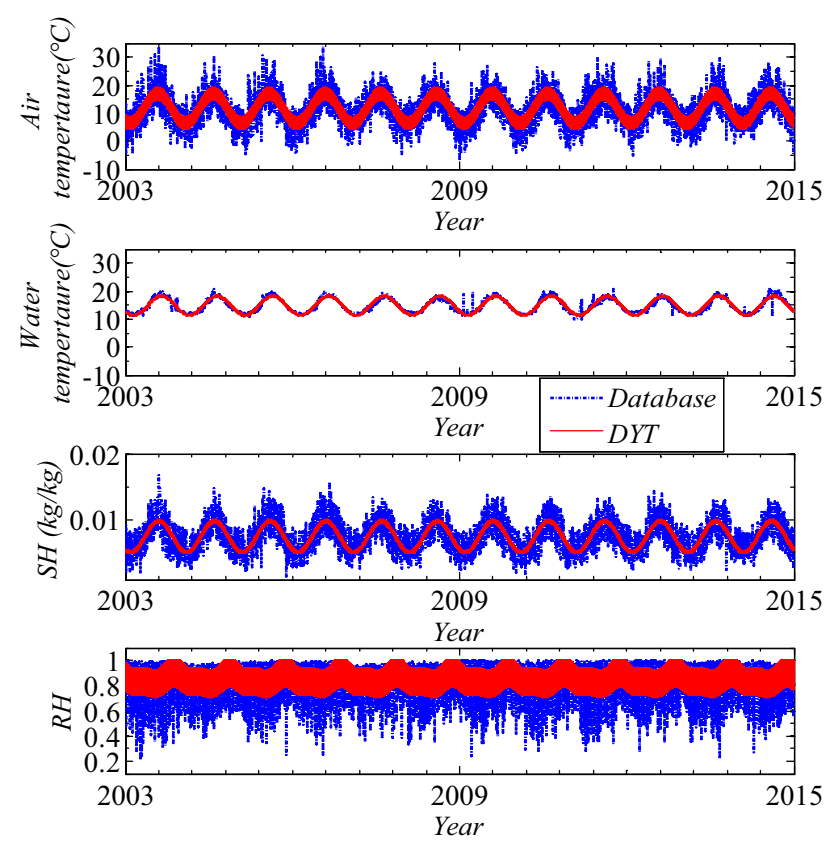

Fig. 2 Climate database and daily yearly-based climate model for Brest.

terms. The parameters of the model are unchanged over the whole considered time. The model for climate parameters is expressed as:

$$
\begin{aligned}
\psi^{\mathrm{s}}(\mathrm{t})= & \underbrace{\frac{1}{\mathrm{n}} \sum_{\mathrm{i}=1}^{\mathrm{n}} \psi_{\mathrm{i}}^{\mathrm{s}}}_{\text {mean }}+\underbrace{\psi_{1}^{\mathrm{s}} \times \sin \left(\frac{2 \pi \mathrm{t}}{365.25 \times 24}+\psi_{2}^{\mathrm{s}}\right)}_{\text {seasonal variation }} \\
& +\underbrace{\psi_{3}^{\mathrm{s}} \times \sin \left(\frac{2 \pi \mathrm{t}}{24}+\psi_{4}^{\mathrm{s}}\right)}_{\text {daily variation }}
\end{aligned}
$$

where $\psi^{\mathrm{s}}$ is the modeled weather parameter (air temperature $\mathrm{T}_{\mathrm{a}}$, seawater temperature $\mathrm{T}_{\mathrm{w}}$ or specific humidity $\mathrm{SH}$ ), $\mathrm{n}$ is the
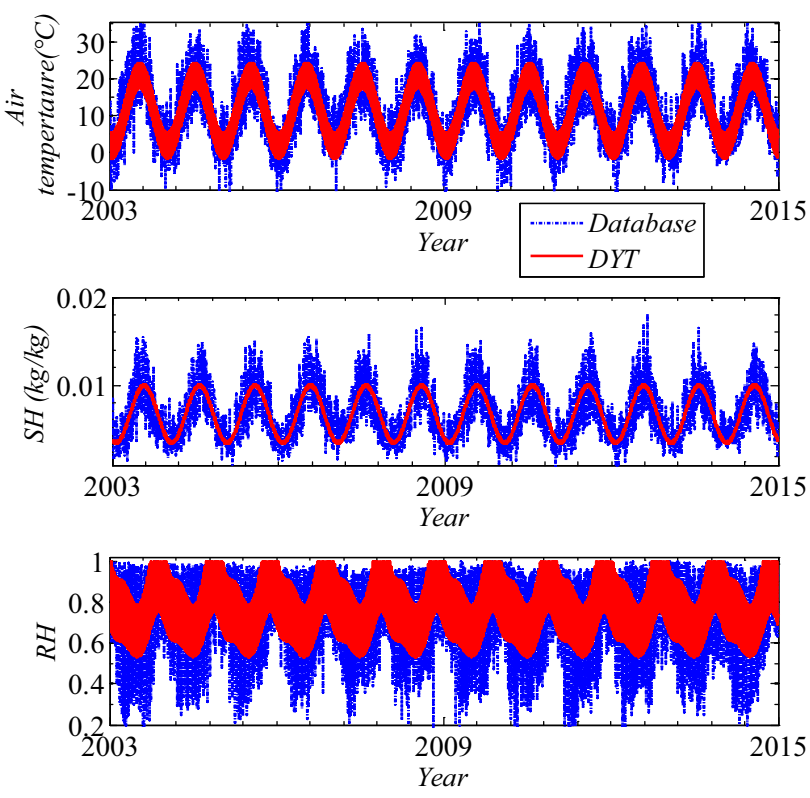

Fig. 3 Climate database and daily yearly-based climate model for Strasbourg.

number of measurement data, and the factors $\psi_{1}^{\mathrm{s}}, \psi_{2}^{\mathrm{s}}, \psi_{3}^{\mathrm{s}}$, and $\psi_{4}^{\mathrm{s}}$ are obtained by fitting the climate model with the database.

Modeling relative humidity variations requires working on specific humidity SH with respect to conservation of mass because this parameter does not depends on air body temperature and pressure changes. $\mathrm{SH}$ is a ratio of the water vapor content to the total air content on a mass basis $\left(\mathrm{m}^{-3} /\right.$ $\mathrm{m}^{3}$ ). The relative humidity can be determined from (Bastidas-Arteaga et al. 2013):

$$
\mathrm{RH}=\frac{\mathrm{SH}}{\exp \left(13.7-\frac{5120}{\mathrm{~T}}\right) \times(\mathrm{SH}+0.622)}
$$

In order to model climate evolution, we choose the climate data over the period of 13 years from 2003 to 2015 as input 

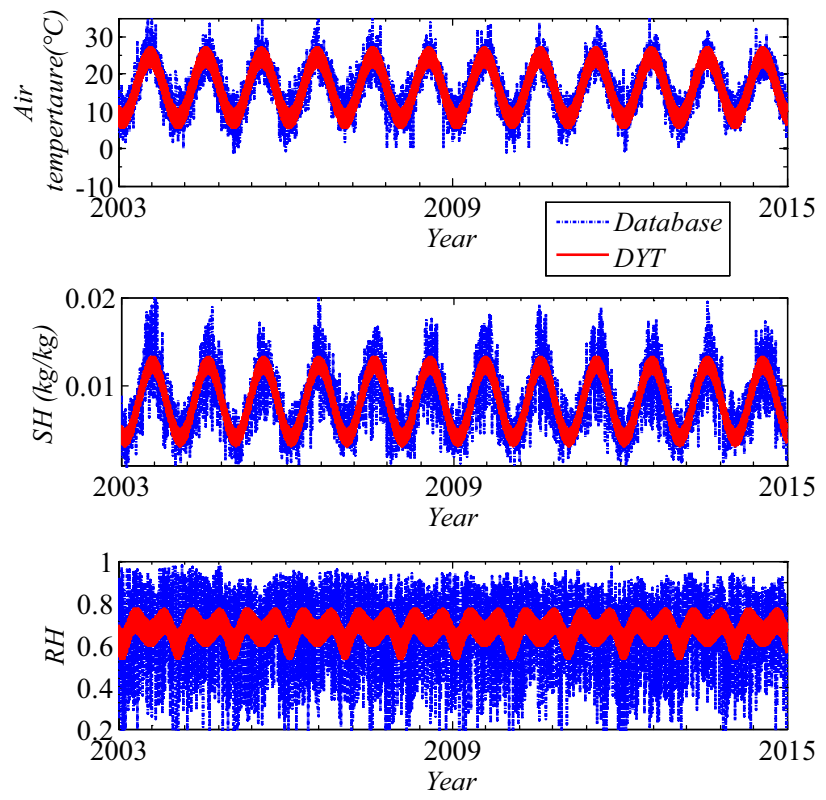

Fig. 4 Climate database and daily yearly-based climate model for Nice.

database. Figures 2, 3 and 4 compare the database with the results of the daily yearly-based climate model. To estimate accuracy of the climate model, we calculate the sum of squares due to error between database and climate model. It was found that the error of the climate models are about 34 , 8 and $43 \%$ for air temperature, water temperature and specific humidity in Brest, respectively. For Strasbourg, we estimate air temperature and specific humidity errors of 25 and $33 \%$, respectively. For Nice, the errors were 13 and $30 \%$ for air temperature and specific humidity, respectively. These results indicate that this climate model represent quite well daily temperature variations of seawater but it cannot represent correctly extreme values of air temperature and specific humidity. This is due to the fact that when we use a yearly-based database to characterize the daily variation term of Eq. (26) the model identifies the same amplitude parameter $\psi_{3}^{\text {s }}$ for all months. Figure 4 shows that the daily yearlybased model is not well adapted to represent this kind of climate; in particular, for modeling relative humidity variations.

\subsubsection{Daily Climate Model Considering a Monthly Type Day (DMT)}

This climate model also takes into account average, seasonal and daily climate variations as in Eq. (26). However, in this climate model we are interested in characterizing a daily climate variation for each month. Figure 5 shows the daily climate variation of August 2005 in Brest, France obtained from above-mentioned models. In comparison with the daily yearly-based model, this model provides a better representation of daily climate variations.

\subsubsection{Seasonal Climate Model}

This model only considers climate average and seasonal climate variation terms only:
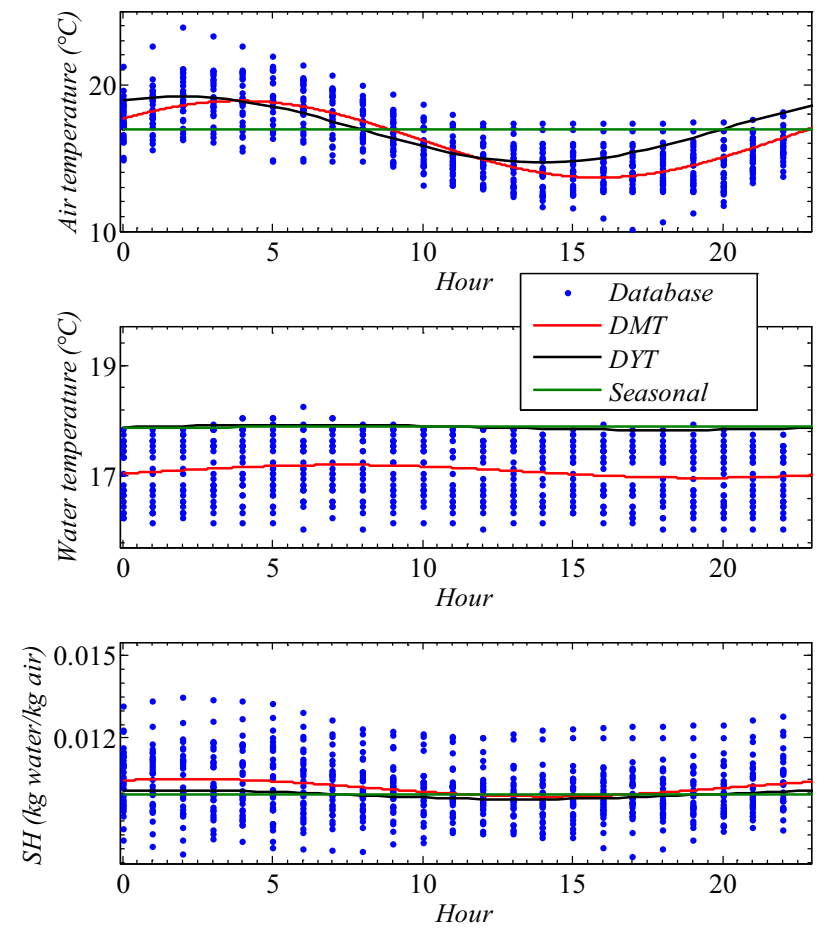

Fig. 5 Determination of the daily monthly-based model, August, 2005 in Brest, France.

$$
\psi^{\mathrm{s}}(\mathrm{t})=\underbrace{\frac{1}{\mathrm{n}} \sum_{\mathrm{i}=1}^{\mathrm{n}} \psi_{\mathrm{i}}^{\mathrm{s}}}_{\text {climate average }}+\underbrace{\psi_{1}^{\mathrm{s}} \times \sin \left(\frac{2 \pi \mathrm{t}}{365.25 \times 24}+\psi_{2}^{\mathrm{s}}\right)}_{\text {seasonal variation }}
$$

This is a common model used to simulate seasonal climate variations in the literature (Martin-Pérez 1999). However, Fig. 5 shows that there is an important scatter in comparison with hourly climate variations. The following section explores how the approximations of climate models influence long-term chloride ingress assessment.

\section{Illustrative Example}

\subsection{Problem Description}

In order to compare the complete and reduced chloride ingress models, one specific chloride-contaminated environment is assigned to each location (Table 1). These exposures correspond to a tidal zone with wetting-drying cycles, a cold inland area where chlorides come from deicing salts and a coastal zone were chlorides are carried by salt spray for Brest, Strasbourg and Nice, respectively. It should be noted that the surface total chloride concentration $\mathrm{C}_{\mathrm{s}}$ is used for structures placed in Strasbourg and Nice. The used values are also detailed in Table 1. For the structure sited in a tidal zone (Brest), we imposed a free chloride concentration $\mathrm{C}_{\mathrm{f}}$ at the concrete surface corresponding to the seawater $(17.75 \mathrm{~kg} / \mathrm{m} 3$ water) concentration during the immersion period (high tide). During low tide, the chloride flux at the surface of the concrete is zero. The isotherm 
Table 1 Exposure conditions for each location.

\begin{tabular}{|c|c|c|c|}
\hline Location & Description of exposure conditions & $\mathrm{C}_{\mathrm{s}}$ & References \\
\hline Brest & \begin{tabular}{|} 
Coastal structure placed in a tidal \\
zone with one cycle of wetting \\
$(6 \mathrm{~h})$ and drying $(18 \mathrm{~h})$ per day
\end{tabular} & $\mathrm{C}_{\mathrm{f}}=17.75 \mathrm{~kg} / \mathrm{m}^{3}$ water & Sleiman et al. (2009) \\
\hline Strasbourg & $\begin{array}{c}\text { Inland structure located in a cold } \\
\text { region where de-icing salts are } \\
\text { applied during a winter period of } \\
5 \text { months (from October to } \\
\text { February). This cold period } \\
\text { length was assumed based on } \\
\text { recorded weather data }\end{array}$ & $3.5 \mathrm{~kg} / \mathrm{m}^{3}$ concrete & Bastidas-Arteaga et al. (2013) \\
\hline Nice & $\begin{array}{c}\text { Structures placed at } 0.1 \mathrm{~km} \text { from } \\
\text { the seashore. Chlorides are } \\
\text { carried by salt spray from sea } \\
\text { chlorides mixed in the humid air. } \\
\text { The surface chloride } \\
\text { concentration is constant during } \\
\text { the structural lifetime }\end{array}$ & $2.95 \mathrm{~kg} / \mathrm{m}^{3}$ concrete & Martin-Pérez (1999) \\
\hline
\end{tabular}

equation is used to calculate the total chloride concentration $\mathrm{C}_{\mathrm{s}}$.

We also consider that the three $\mathrm{RC}$ structures were built using the same concrete that contains $330 \mathrm{~kg} / \mathrm{m}^{3}$ of ordinary Portland cement, $8 \%$ of $\mathrm{C}_{3} \mathrm{~A}$ and $\mathrm{w} / \mathrm{c}=0.5$. It is assumed that the hydration period $t_{\text {ref }}$, equal 28 days [Eq. (15)]. The main parameters of the considered concrete are described in Table 2.
4.2 Results: Chloride Transfer Model and TimeStep Effect

The following results focus on the comparison of the total chloride concentration estimated by both the complete and reduced models at the cover depth $(5 \mathrm{~cm})$. They also study the effect of the time-step used for averaging the climate database, dt - e.g., hourly, daily, weekly, etc. The results are compared with the reference cases using time discretization

Table 2 Material parameters (Samson and Marchand 2007; Nguyen 2007).

\begin{tabular}{|c|c|c|c|}
\hline Physical problem & Parameter & Unit & Value \\
\hline \multirow[t]{7}{*}{ Moisture transport } & $\alpha$ & - & 3.82 \\
\hline & $\beta$ & - & 0.47 \\
\hline & $\mathrm{m}$ & - & 1.40 \\
\hline & $\mu_{\mathrm{w}}$ & $\mathrm{Pa} \times \mathrm{s}$ & $1 \times 10^{-3}$ \\
\hline & $\mathrm{K}_{\mathrm{w}}$ & $\mathrm{m}^{2}$ & $3 \times 10^{-21}$ \\
\hline & $\mathrm{E}_{\mathrm{h}}$ & $\mathrm{kJ} / \mathrm{mol}$ & 30 \\
\hline & $\epsilon$ & - & 0.12 \\
\hline \multirow[t]{3}{*}{ Heat transfer } & $\lambda_{\text {ref }}$ & $\mathrm{W} / \mathrm{m} \mathrm{K}$ & 2.46 \\
\hline & $\mathrm{C}_{\mathrm{p}}$ & $\mathrm{J} / \mathrm{kg} \mathrm{C}$ & 1000 \\
\hline & $\rho_{0}$ & $\mathrm{Kg} / \mathrm{m}^{3}$ & 2400 \\
\hline \multirow[t]{7}{*}{ Chloride ingress } & $\mathrm{D}_{\mathrm{Cl}, \text { ref }}$ & $\mathrm{m}^{2} / \mathrm{s}$ & $3 \times 10^{-12}$ \\
\hline & $\mathrm{E}_{\mathrm{a}}$ & $\mathrm{kJ} / \mathrm{mol}$ & 35 \\
\hline & $\alpha_{i}$ & $\mathrm{~m}^{3}$ solution $/ \mathrm{m}^{3}$ concrete & 0.38 \\
\hline & $\beta_{\mathrm{i}}$ & $\mathrm{m}^{3}$ solution $/ \mathrm{mol}$ chloride & 0.07 \\
\hline & $\mathrm{m}_{\text {age }}$ & - & 0.15 \\
\hline & $\mathrm{m}_{\mathrm{ion}}$ & - & 0.50 \\
\hline & $\mathrm{k}_{\text {ion }}$ & - & 8.33 \\
\hline
\end{tabular}


step of $1 \mathrm{~h}$. As mentioned in Sect. 2.4, the simulations are stopped once corrosion initiation takes place or after 100 years of exposure.

\subsubsection{Exposure to a Tidal Zone}

Figure 6 compares the complete and the reduced models for various values of time step dt. The overall evolution of the chloride concentration curves confirms previous results of the literature that chloride penetrates very fast into RC structures located in tidal zone (Amiri et al. 2015). We found that the use of the reduced model of chloride ingress does not affect chloride concentration at the steel level. The computational error compared to the complete model is about $1 \%$ according to Table 3. Figure 6 also shows that there is a small influence of the considered time-steps $(\mathrm{dt}=1 \mathrm{~h}$ and $\mathrm{dt}=6 \mathrm{~h})$ on the chloride concentration at the steel level. These two small time-steps were selected because the RC structure is subjected to $6-18 \mathrm{~h}$ wetting-drying cycles. The small difference could be explained by the imposed environmental conditions. The structure is exposed to seawater during a quarter of the day where it is subjected to a saturated environment with small temperature fluctuations (Fig. 7). Therefore, accounting for hourly variations during the drying period does not affect significantly the chloride ingress process.

We can note that for the weather condition and type of exposure, some terms of chloride ingress equations, such as vapor diffusion or thermo-diffusion does not play important roles for a concrete subjected to larger relative humidity. In particular, when we focus on the assessment of chloride ingress at the cover rebar. It was also found that a time-step with the length of the drying cycles reduces in ten times computational effort without adding significant errors (Table 3). However, different results could be obtained for larger lengths of the drying cycles.

\subsubsection{Exposure to Chloride from De-lcing Salts}

For this type of exposure, we consider various time-steps from $1 \mathrm{~h}$ to 7 days. According to the results displayed in Fig. 8, we found that there is no significant difference

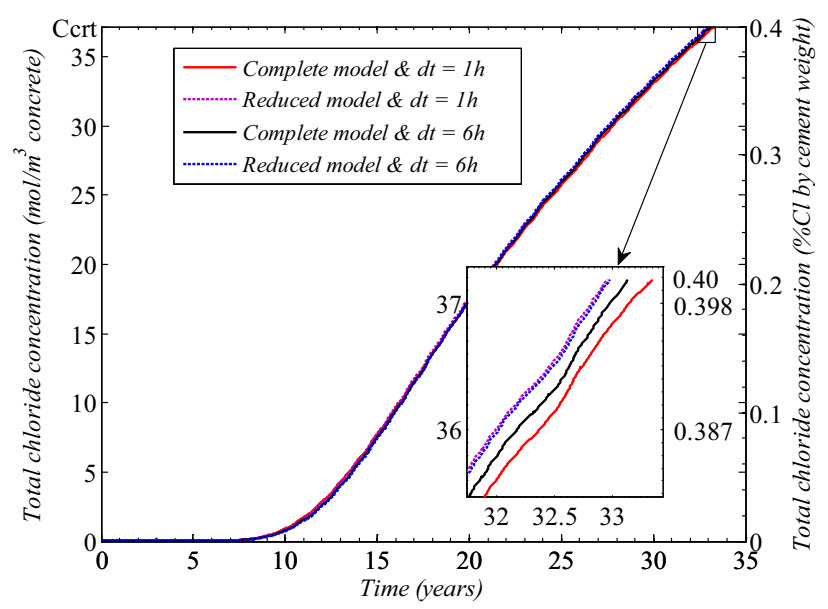

Fig. 6 Comparison of models considering various time-steps for a RC structure in a tidal zone (Brest, France). between complete and reduced models as in the previous case. In contrast, when the time-step increases, chloride concentrations for a given exposure year are underestimated with respect to the reference case $(\mathrm{dt}=1 \mathrm{~h})$. This difference can reach $11.3 \%$ with a 7 days-time step against $7 \%$ with a 24 h-time step (Table 3). The computational errors are related to the approximations for averaging the mean environmental data during each time-step (Fig. 9). It is observed that the approximation error increases for larger time-step. For temperature, these errors are: $4 \%$ for $\mathrm{dt}=6 \mathrm{~h}, 14 \%$ for $\mathrm{dt}=24 \mathrm{~h}$ and $22 \%$ for $\mathrm{dt}=7$ days. The errors are mainly related to the omission of maximum or minimum values of environmental parameters during the assessment of the average value for each dt. Despite of an interesting computational gain when $\mathrm{dt}>6 \mathrm{~h}$ (Table 3 ), the computational errors induce an overestimation from 3 to 5 years of the corrosion initiation time assessment. Therefore, we suggest for this kind of exposure to use a reduced model of chloride ingress with $\mathrm{dt}=6 \mathrm{~h}$ that is 14.6 times faster in comparison with the reference case (complete model with $\mathrm{dt}=1 \mathrm{~h}$ ).

\subsubsection{Exposure to Chlorides from Salt Spray}

Through the results shown in Fig. 10, we found that the difference between the complete and reduced models is negligible. However, we observe that the assessment of chloride ingress is significantly reduced for large time-steps. For instance, Table 3 indicates that the computational error can reach $23.4 \%$ for $\mathrm{dt}=7$ days. This is mainly related to the specific climate of Nice (Fig. 4). Figure 11 shows that the average value estimated for each time-step is still larger in comparison to the other places (Brest and Strasbourg). Dryness of Nice weather decreases the chloride ingress rate. It should be noted that the computation was stopped at 100 years before corrosion initiation. Once the climate data is averaged during dt the larger values of relative humidity are neglected inducing an additional reduction of this chloride ingress rate. Thereby, the reduced model of chloride ingress with $\mathrm{dt}=6 \mathrm{~h}$ can be also used to predict chloride ingress for this kind of exposure. This configuration allows a gain of 7.6 times of computational effort with respect to the complete model.

\subsection{Results: Climate Prediction Effect}

This section estimates the effect of using the three abovementioned climate models (Sect. 3.2) for assessing the total chloride ingress at the cover depth $(5 \mathrm{~cm})$. The results account for the following considerations:

- The parameters of the climate models are determined from the climate database by considering various lengths and periods of data for identification (Table 4).

- The chloride ingress at the rebar is assessed from the reduced model with a time-step $\mathrm{dt}=6 \mathrm{~h}$.

- The evaluation of the impact of climate models considers mid- and long-term exposure times (20 and 50 years, respectively).

Figure 12 presents the evolution in time of total chloride content at the rebar depth for all exposures and models. It is 
Table 3 Computational impact analysis for the reduced chloride ingress model.

\begin{tabular}{c|c|c|c|c}
\hline \multirow{2}{*}{ Exposure } & Time-step & $\begin{array}{c}\text { Time to assess error and } \\
\text { gain } \\
\text { (year) }\end{array}$ & $\begin{array}{c}\text { Computational error } \\
\text { (\%) }\end{array}$ & Computational gain $^{\text {b }}$ \\
\hline \hline \multirow{2}{*}{$\begin{array}{c}\text { Tidal zone } \\
\text { (Brest) }\end{array}$} & $\mathrm{dt}=1 \mathrm{~h}$ & 32.82 & 1.2 & 2.2 \\
\cline { 2 - 5 } & $\mathrm{dt}=6 \mathrm{~h}$ & 32.85 & 0.1 & 2.1 \\
\hline \multirow{2}{*}{$\begin{array}{c}\text { De-icing salts } \\
\text { (Strasbourg) }\end{array}$} & $\mathrm{dt}=1 \mathrm{~h}$ & 51.65 & 1.0 & 14.6 \\
\cline { 2 - 5 } & $\mathrm{dt}=6 \mathrm{~h}$ & 52.22 & 7.0 & 53.0 \\
\cline { 2 - 5 } & $\mathrm{dt}=24 \mathrm{~h}$ & 55.34 & 0.1 & 279.0 \\
\hline \multirow{2}{*}{$\begin{array}{c}\text { Salt spray } \\
\text { (Nice) }\end{array}$} & $\mathrm{dt}=7 \mathrm{days}$ & 57.59 & 0.1 & 1.4 \\
\cline { 2 - 5 } & $\mathrm{dt}=1 \mathrm{~h}$ & 100 & 7.5 & 7.6 \\
\cline { 2 - 5 } & $\mathrm{dt}=6 \mathrm{~h}$ & 100 & 23.4 & 28.4 \\
\hline
\end{tabular}

${ }^{a}$ Absolute error estimated with respect to the complete model with $\mathrm{dt}=1 \mathrm{~h}$.

${ }^{\mathrm{b}}$ Computed as the ratio between the total simulation time for the complete model with $\mathrm{dt}=1 \mathrm{~h}$ divided by the total simulation time in each case.
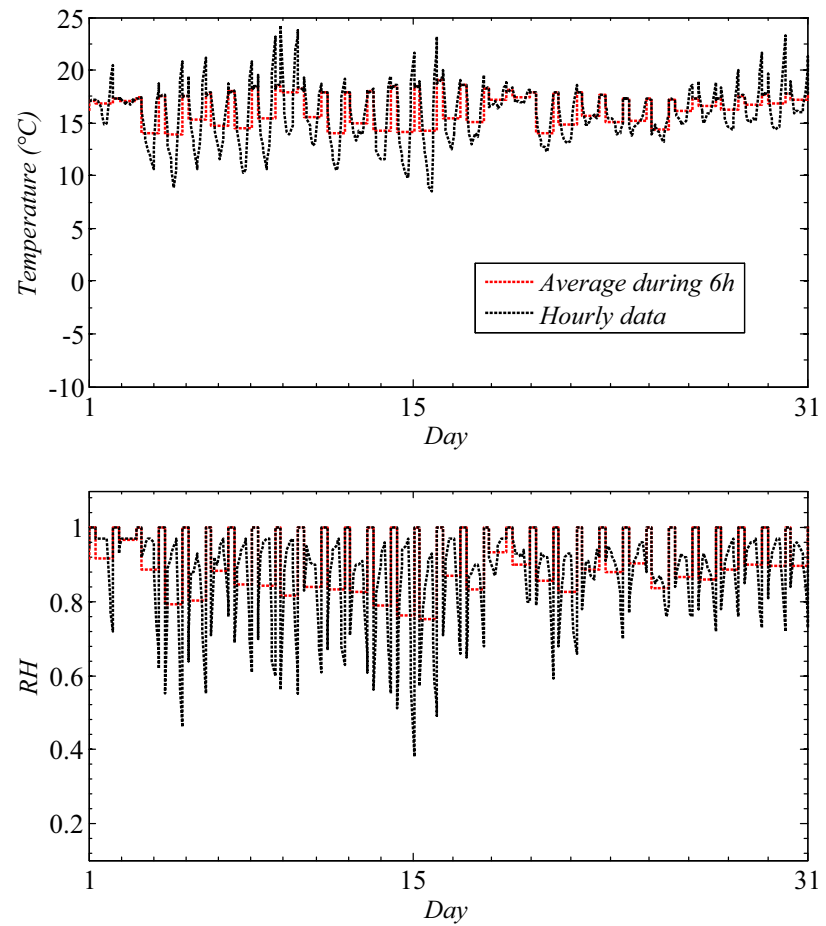

Fig. 7 Environmental and imposed boundary conditions for a month, in Brest, France.

observed that the influence of the considered climate model varies for each environmental condition. For Brest, it was found that the total chloride concentrations obtained from the real database and all climate models are very close. Table 4 indicates that the maximum absolute difference is smaller than $1.56 \mathrm{~mol} / \mathrm{m}^{3}$ concrete. This value represents about $4 \%$ of the critical chloride concentration for corrosion initiation. The small differences between models and database results are explained by the fact that the structure is subjected to seawater environmental conditions under $25 \%$

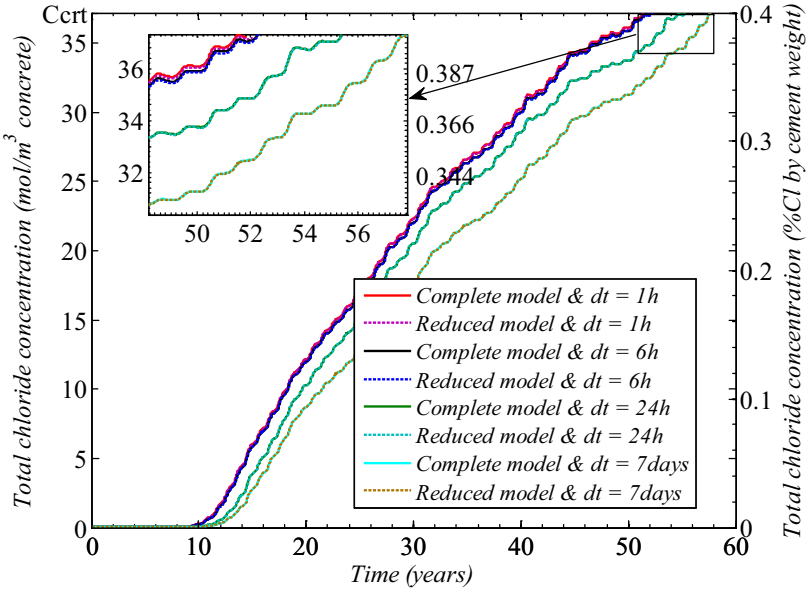

Fig. 8 Comparison of models considering various time-steps for a RC structure subjected to de-icing salt in Strasbourg, France.

of exposure time. Since seawater environmental conditions follow a sinusoidal trend (Fig. 2), the approximations for climate models, for air temperature and relative humidity do not have a large influence on the chloride ingress assessment. Therefore, the simplest model based on seasonal variations can be used to predict the durability of $\mathrm{RC}$ structures placed in tidal zones when the immersion time is larger.

For Strasbourg, the daily monthly-based or yearly-based models seem to be good approaches with respect to the realistic climate data in short- and long-term assessments. However, the performance of daily monthly-based models (DMT) depends on the length of the training database. It was found that a 13 years training database improves long-term chloride ingress assessment. In contrast, the differences with respect to the reference case (Table 4) were largest when the training was done for only 1 year. At 50 years these 


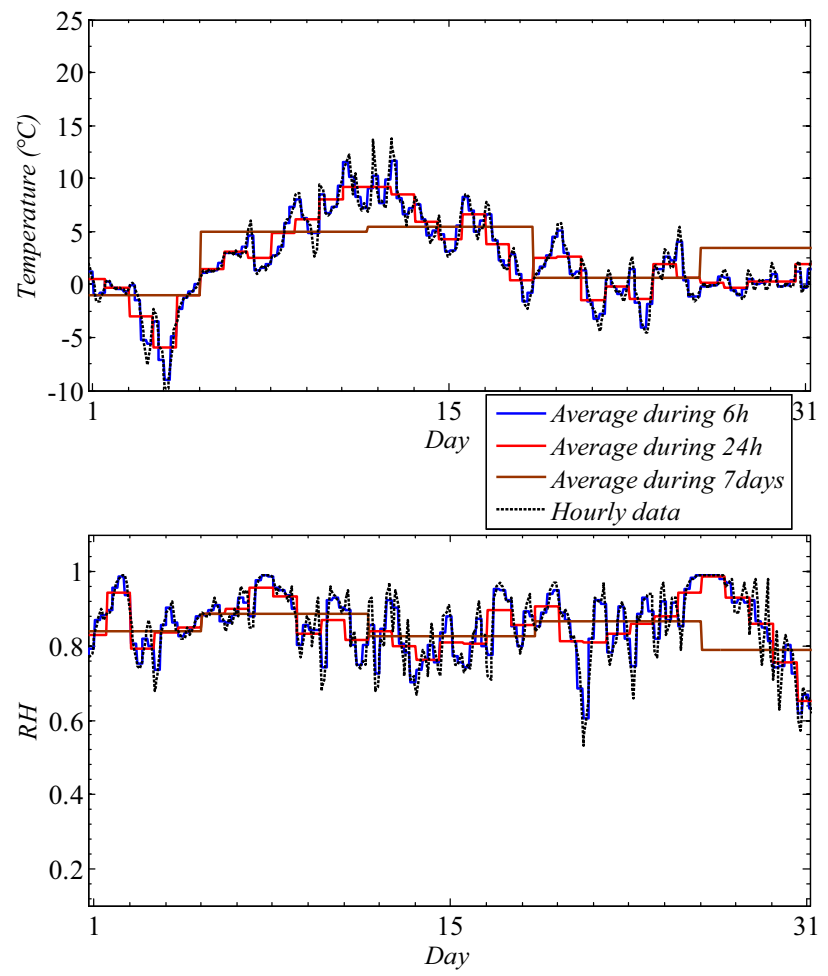

Fig. 9 Environmental data averaged during various timesteps for a month in Strasbourg, France.

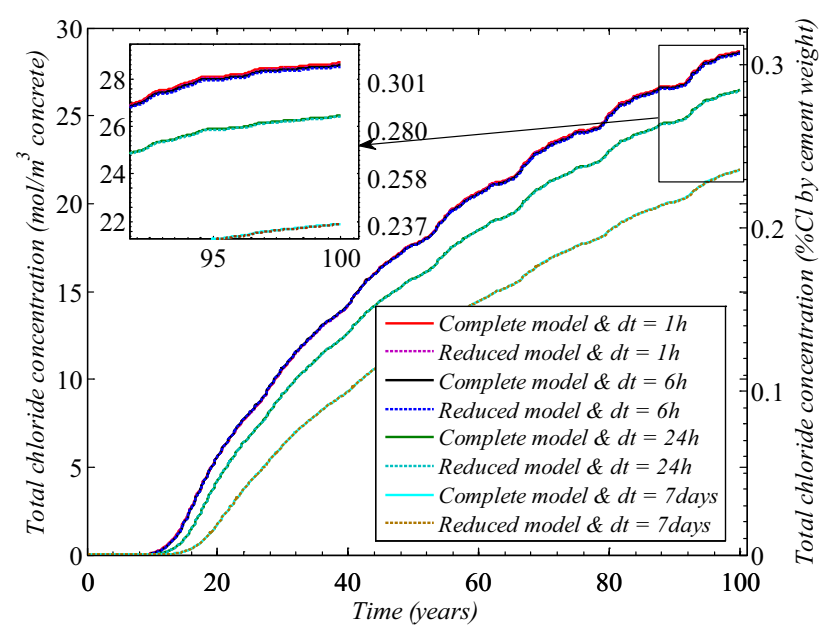

Fig. 10 Comparison of models considering various timesteps for a RC subjected to salt spray in Nice, France.

differences are superior to $4 \mathrm{~mol} / \mathrm{m}^{3}$ concrete (about $11 \%$ of $\mathrm{C}_{\text {crt }}$ ) and increase with time. These results indicate that for this kind of exposure and climate the assessment of chlorideinduced corrosion risks is very sensitive to the choice of the climate model as well as the training period for the DMT. It is therefore recommended to use a daily yearly-based model with a long training period.

Concerning Nice, the results indicate that DMT reduce the differences in comparison to the reference case (Table 4). Contrarily to Strasbourg results, the difference decreases when the training period is shorter (1 years). This should be related to important climate variations that are neglected by the sinusoidal trend when the model parameters are

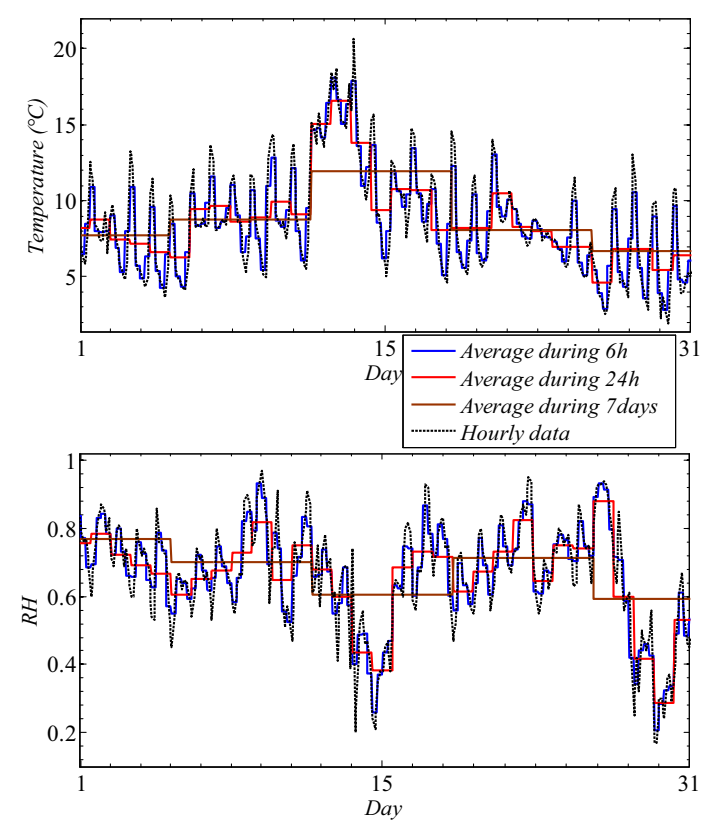

Fig. 11 Environmental data averaged during various timesteps for a month, in Nice, France.

identified over larger training periods. It can be observed from Fig. 4 that this approximation for a training period of 13 years underestimates larger relative humilities that are paramount for assessment of chloride ingress into $\mathrm{RC}$ structures located in aerial zones. For this reason, all climate models underestimate chloride ingress. Although the difference for DMT with a year of training is approximately $1 \mathrm{~mol} / \mathrm{m}^{3}$ concrete (about $2 \%$ of $\mathrm{C}_{\text {crt }}$ ), indicates that it should increase with time by adding errors for the corrosion initiation estimation.

The studied climate models only take into account deterministic trends. The assessment could be improved by including the randomness of the problem (e.g., by adding a stochastic term to the climate model) to account for extreme weather conditions that accelerate of decelerate deterioration processes. The models could also include climate change effects to study the concrete behavior under new environmental constraints. Some studies have included these aspects for probabilistic assessment of corrosion initiation (Bastidas-Arteaga et al. 2013; Breysse et al. 2014).

\section{Conclusions}

This paper presented some considerations to predict chloride ingress into unsaturated concrete under realistic exposure and weather conditions. A complete model of chloride ingress that couples moisture, heat and chloride transfers is first formulated. Since this complete model requires significant computational time, a reduced model of chloride ingress is afterwards proposed. The comparison of both models showed that they nearly provide similar results for the three considered exposure conditions: tidal, de-icing salt, and salt spray zones. 
Table 4 Mid- and long-term differences between chloride concentrations assessed with the climate database and models $\left(\mathrm{mol} / \mathrm{m}^{3}\right.$ concrete).

\begin{tabular}{c|c|c|c|c|c|c|c}
\hline Climate model & $\begin{array}{c}\text { Length and } \\
\text { period of climate } \\
\text { database }\end{array}$ & \multicolumn{3}{|c|}{ 20 year } & \multicolumn{2}{c}{50 year } \\
\cline { 3 - 7 } & $\begin{array}{c}13 \text { year } \\
(2003-2015)\end{array}$ & 0.84 & -0.43 & -5.05 & -0.81 & -0.22 & -8.5 \\
\hline \hline DYT & $\begin{array}{c}13 \text { year } \\
(2003-2015)\end{array}$ & 1.56 & -0.61 & -4.3 & 0.41 & 0.27 & -6.52 \\
\hline DMT & $\begin{array}{c}8 \text { year } \\
(2003-2010)\end{array}$ & 1.52 & 0.23 & -3.18 & 0.33 & 0.6 & -4.57 \\
\hline DMT & $\begin{array}{c}3 \text { year } \\
(2003-2005)\end{array}$ & 1.55 & -1.74 & -2.7 & 0.4 & -1.31 & -3.6 \\
\hline DMT & 1 year (2009) & 1.08 & 1.13 & -0.92 & -0.23 & 4.07 & -0.62 \\
\hline DMT & 1 year (2015) & 1.11 & 1.8 & -1.16 & -0.2 & 4.09 & -1.04 \\
\hline Seasonal & $\begin{array}{c}13 \text { year } \\
(2003-2015)\end{array}$ & 1.19 & -3.24 & -4.16 & -0.03 & -1.01 & -5.89 \\
\hline
\end{tabular}
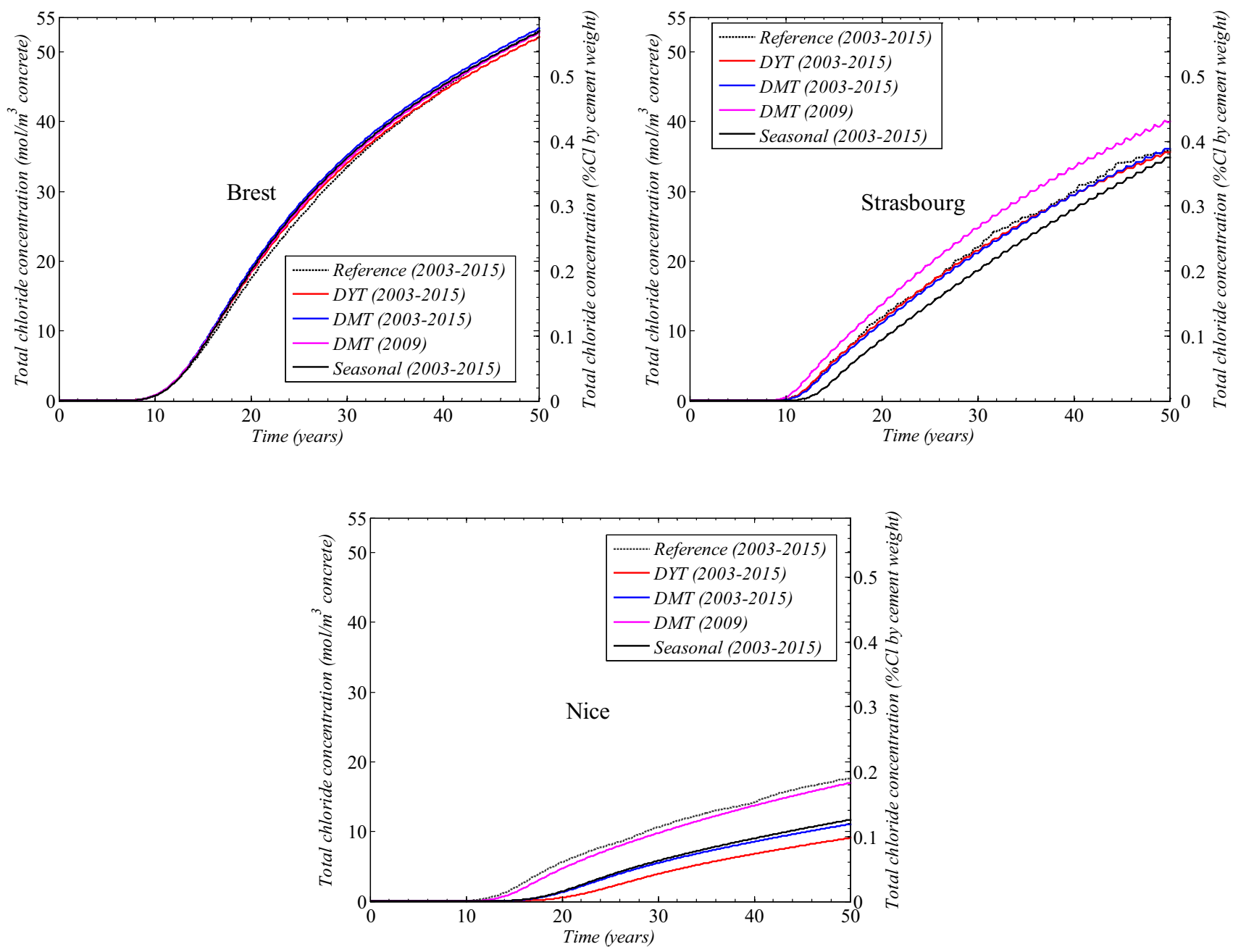

Fig. 12 Evolution of total chloride concentration at the cover depth for climate database and models.

This study also included the effect of the time-step for discretizing environmental databases. For all weather conditions, it was found that a time-step of $6 \mathrm{~h}$ provides an accurate calculation of chloride concentration and reduced the computational effort from 7.6 to 14.6 times with respect to the complete model.

The influence of three climate models was also studied in this paper. The results indicated that the selection of climate 
models as well as the training period could introduce significant errors for mid- and long- term chloride ingress assessment. Consequently, it was recommended to analyze the effects of selecting a given climate model in order to reduce prediction errors.

Further applications will focus on:

- propagating uncertainties (material, model and environmental exposure) throughout the reduced model in order to estimate the probability of corrosion initiation using surrogate modeling techniques; and

- studying the long-term effect of climate change on RC durability.

\section{Acknowledgements}

The authors would like also to acknowledge the support of the 'Pays de la Loire' region through the project RIADAPTCLIM 'International Network on Risk Assessment and Climate Adaptation for Infrastructure and Buildings'. We are also grateful for the insightful and constructive comments from the reviewers.

\section{Open Access}

This article is distributed under the terms of the Creative Commons Attribution 4.0 International License (http://creativecommons.org/licenses/by/4.0/), which permits unrestricted use, distribution, and reproduction in any medium, provided you give appropriate credit to the original author(s) and the source, provide a link to the Creative Commons license, and indicate if changes were made.

\section{References}

Amiri, O., Aït-Mokhtar, A., Sleiman, H., \& Nguyen, P.-T. (2015). Chloride transport in unsaturated concrete. In A. Aï-Mokhtar \& O. Millet (Eds.), Structure design and degradation mechanisms in coastal environments (pp. 161-196). New York: Wiley.

Andrade, C., \& Alonso, C. (1996). Durability design based on models for corrosion rates. In H. Jennings, J. Kropp, \& K. Scrivener (Eds.), The modelling of microstructure and its potential for studying transport properties and durability (pp. 473-492). Dordrecht: Springer.

Baroghel-Bouny, V., Mainguy, M., Lassabatere, T., \& Coussy, O. (1999). Characterization and identification of equilibrium and transfer moisture properties for ordinary and highperformance cementitious materials. Cement and Concrete Research, 29(8), 1225-1238. doi:10.1016/S0008-8846(99) 00102-7.

Baroghel-Bouny, V., Thiéry, M., \& Wang, X. (2011). Modelling of isothermal coupled moisture-ion transport in cementitious materials. Cement and Concrete Research, 41(8), 828-841. doi:10.1016/j.cemconres.2011.04.001.

Bastidas-Arteaga, E., Chateauneuf, A., Sánchez-Silva, M., Bressolette, P., \& Schoefs, F. (2010). Influence of weather and global warming in chloride ingress into concrete: A stochastic approach. Structural Safety, 32(4), 238-249. doi: 10.1016/j.strusafe.2010.03.002.

Bastidas-Arteaga, E., Chateauneuf, A., Sánchez-Silva, M., Bressolette, P., \& Schoefs, F. (2011). A comprehensive probabilistic model of chloride ingress in unsaturated concrete. Engineering Structures, 33(3), 720-730. doi: 10.1016/j.engstruct.2010.11.008.

Bastidas-Arteaga, E., \& Schoefs, F. (2012). Stochastic improvement of inspection and maintenance of corroding reinforced concrete structures placed in unsaturated environments. Engineering Structures, 41, 50-62. doi:10.1016/ j.engstruct.2012.03.011.

Bastidas-Arteaga, E., \& Schoefs, F. (2015). Sustainable maintenance and repair of RC coastal structures. Proceedings of the ICE-Maritime Engineering, 168(4), 162-173.

Bastidas-Arteaga, E., Schoefs, F., Stewart, M. G., \& Wang, X. (2013). Influence of global warming on durability of corroding RC structures: A probabilistic approach. Engineering Structures, 51, 259-266. doi:10.1016/j.engstruct. 2013.01.006.

Bastidas-Arteaga, E., \& Stewart, M. G. (2015). Damage risks and economic assessment of climate adaptation strategies for design of new concrete structures subject to chlorideinduced corrosion. Structural Safety Part A, 52, 40-53. doi: 10.1016/j.strusafe.2014.10.005.

Bhide, S. (2008). Material Usage and Condition of Existing Bridges in the U.S. Skokie: Portland Cement Association.

Breysse, D., Chaplain, M., Marache, A., \& Rodney, E. (2014). Simulation of synthetic climate at local scale as a mean to assess the impact of climate change on infrastructures. Civil Engineering and Environmental Systems, 31(2), 165-178. doi:10.1080/10286608.2014.912643.

Buchwald, A. (2000). Determination of the ion diffusion coefficient in moisture and salt loaded masonry materials by impedance spectroscopy. 3rd international PhD symposium, 2, 475.

Damrongwiriyanupap, N., Limkatanyu, S., Xi, Y., Limkatanyu, S., \& Xi, Y. (2015). A thermo-hygro-coupled model for chloride penetration in concrete structures. Advances in Materials Science and Engineering, 2015, e682940. doi: 10.1155/2015/682940.

De Vera, G., Climent, M. A., Viqueira, E., Antón, C., \& López, M. P. (2015). Chloride penetration prediction in concrete through an empirical model based on constant flux diffusion. Journal of Materials in Civil Engineering, 27(8), 04014231.

de Vera, G., Hidalgo, A., Climent, M. A., Andrade, C., \& Alonso, C. (2000). Chloride-ion activities in simplified synthetic concrete pore solutions: The effect of the accompanying ions. Journal of the American Ceramic Society, 83(3), 640-644. doi:10.1111/j.1151-2916.2000. tb01245.x. 
Duracrete. (2000). Statistical quantification of the variables in the limit state functions, DuraCrete-Probabilistic performance based durability design of concrete structures (vol. EU-Brite EuRam III. Contract BRPR-CT95-0132, project BE95-1347/R9).

Flint, M., Michel, A., Billington, S. L., \& Geiker, M. R. (2014). Influence of temporal resolution and processing of exposure data on modeling of chloride ingress and reinforcement corrosion in concrete. Materials and Structures, 47(4), 729-748. doi:10.1617/s11527-013-0091-8.

Genuchten, M. (1980). A closed-form equation for predicting the hydraulic conductivity of unsaturated soils. Soils Science of America Journal, 44, 892-898.

Hidalgo, A., De Vera, G., Climent, M. A., Andrade, C., \& Alonso, C. (2001). Measurements of chloride activity coefficients in real portland cement paste pore solutions. Journal of the American Ceramic Society, 84(12), 3008-3012. doi:10.1111/j.1151-2916.2001.tb01128.x.

Imam, A., Anifowose, F., \& Azad, A. K. (2015). Residual strength of corroded reinforced concrete beams using an adaptive model based on ANN. International Journal of Concrete Structures and Materials, 9, 159. doi: 10.1007/s40069-015-0097-4.

Jensen, O. M., \& Hansen, P. F. (1999). Influence of temperature on autogenous deformation and relative humidity change in hardening cement paste. Cement and Concrete Research, 29(4), 567-575.

Kim, H. R., Choi, W. C., Yoon, S. C., et al. (2016). Evaluation of bond properties of reinforced concrete with corroded reinforcement by uniaxial tension testing. International Journal of Concrete Structures and Materials, 10(Suppl 3), 43. doi:10.1007/s40069-016-0152-9.

Larsen, C. K. (1998). Chloride binding in concrete-effect of surrounding environment and concrete composition. $\mathrm{PhD}$ thesis. The Norwegian University of Science and Technology.

Liu, Y., \& Weyers, R. E. (1998). Modeling the time to corrosion cracking in chloride contaminated reinforced concrete structures. ACI Materials Journal, 95(6), 675-680.

Marchand, J., \& Samson, E. (2009). Predicting the service-life of concrete structures-Limitations of simplified models. Cement \& Concrete Composites, 31(8), 515-521. doi: 10.1016/j.cemconcomp.2009.01.007.

Martin-Pérez, B. (1999). Service life modeling of R.C. highway structures exposed to chlorides. $\mathrm{PhD}$ thesis. Toronto: University of Toronto.

Morga, M., \& Marano, G. C. (2015). Chloride penetration in circular concrete columns. International Journal of Concrete Structures and Materials, 9(2), 173-183. doi: 10.1007/s40069-014-0095-y.

Mualem, Y. (1976). A new model for predicting the hydraulic conductivity of unsaturated porous media. Water Resources Research, 12(3), 513-522.

Nguyen, T. Q. (2007). Physicochemical modelling of chloride ingresse into cementitious materials. Ph.D. thesis. France.

Nguyen, P. T., \& Amiri, O. (2016). Study of the chloride transport in unsaturated concrete: Highlighting of electrical double layer, temperature and hysteresis effects. Construction and Building Materials, 122, 284-293. doi: 10.1016/j.conbuildmat.2016.05.154.

Nielsen, E. P., \& Geiker, M. R. (2003). Chloride diffusion in partially saturated cementitious material. Cement and Concrete Research, 33(1), 133-138. doi:10.1016/S 0008-8846(02)00939-0.

Pang, L., \& Li, Q. (2016). Service life prediction of RC structures in marine environment using long term chloride ingress data: Comparison between exposure trials and real structure surveys. Construction and Building Materials, 113, 979-987. doi:10.1016/j.conbuildmat.2016.03.156.

Pritzl, M. D., Tabatabai, H., \& Ghorbanpoor, A. (2014). Laboratory evaluation of select methods of corrosion prevention in reinforced concrete bridges. International Journal of Concrete Structures and Materials, 8, 201. doi:10.1007/s 40069-014-0074-3.

Radlińska, A., McCarthy, L. M., Matzke, J., et al. (2014). Synthesis of DOT use of beam end protection for extending the life of bridges. International Journal of Concrete Structures and Materials, 8, 185 . doi:10.1007/s 40069-014-0077-0.

Samson, E., \& Marchand, J. (2007). Modeling the effect of temperature on ionic transport in cementitious materials. Cement and Concrete Research, 37(3), 455-468. doi: 10.1016/j.cemconres.2006.11.008.

Sleiman, H., Amiri, O., \& Aït-Mokhtar, A. (2009). Chloride transport in unsaturated cement-based materials. European Journal of Environmental and Civil Engineering, 13(4), 489-499. doi:10.1080/19648189.2009.9693125.

Srubar, W. V. (2015). Stochastic service-life modeling of chloride-induced corrosion in recycled-aggregate concrete. Cement \& Concrete Composites, 55, 103-111. doi: 10.1016/j.cemconcomp.2014.09.003.

Tang, L., \& Nilsson, L.-O. (1993). Chloride binding capacity and binding isotherms of OPC pastes and mortars. Cement and Concrete Research, 23(2), 247-253.

Tuutti, K. (1982). Corrosion of steel in concrete. Stockholm: Swedish Cement and Concrete Research Institute.

Wang, X., Nguyen, M., Stewart, M. G., Syme, M., \& Leitch, A. (2010). Analysis of Climate Change Impacts on the Deterioration of Concrete Infrastructure - Part 1: Mechanisms, Practices, Modelling and Simulations - A review. Canberra: CSIRO.

Xi, Y., \& Bažant, Z. P. (1999). Modeling chloride penetration in saturated concrete. Journal of Materials in Civil Engineering, 11(1), 58-65.

Yuan, Y., \& Jiang, J. (2011). Prediction of temperature response in concrete in a natural climate environment. Construction and Building Materials, 25(8), 3159-3167. doi:10.1016/ j.conbuildmat.2010.10.008.

Zhang, J., Huang, Y., Qi, K., \& Gao, Y. (2012). Interior relative humidity of normal- and high-strength concrete at early age. Journal of Materials in Civil Engineering, 24(6), 615-622. doi:10.1061/(ASCE)MT.1943-5533.0000441. 